\title{
RODRIGO EN LAS MOCEDADES: ¿VASALLO LEAL O JOVEN REBELDE? ${ }^{1}$
}

\author{
IRENE ZADERENKO
}

Boston University

Desde que la crítica comenzó a interesarse por las Mocedades de Rodrigo en la segunda mitad del siglo XIX, su protagonista ha sido caracterizado como un joven rebelde y arrogante, muy alejado del retrato del vasallo leal y maduro del Poema de mio Cid. Agustín Durán, uno de los primeros editores del texto (al que designó, como se venía haciendo, Crónica rimada), señaló que el joven Rodrigo era "cuasi-feudal y antirrealista», en tanto el del Poema y de las crónicas latinas y castellanas era, en su opinión, «monárquico, devoto y democrático» ${ }^{2}$.

El conde de Puymaigre también oponía el Cid «royaliste» del Poema al «féodal» de las Mocedades, «un Cid qui devait faire bien accueillir par les seigneurs les jongleurs se présentant sous son patronage ${ }^{3}$, y señalaba como prueba de su «arrogance féodale» la negativa de Rodrigo a besar la mano del rey Fernando ${ }^{4}$.

José Amador de los Ríos intentó atenuar las diferencias entre el impetuoso

\footnotetext{
I Agradezco a Ottavio Di Camillo y a Leonardo Funes el haber leído este trabajo y sus valiosos comentarios y sugerencias.

${ }^{2}$ De acuerdo con los ideales románticos de la época, el bibliógrafo y erudito español vio en ef Cid a la figura que representaba ante el monarca los intereses del pueblo y defendía los derechos de éste contra la aristocracia. El héroe castellano del Poema y de la historia, afirma Durán, «eleva su voz contra los aduladores cortesanos que circuyen y corrompen a los reyes, [...] es el que severo y respetuoso, apoyado en la justicia, y mártir de ella, la hace triunfar a costa del mismo martirio; y en fin, es el Cid que ha prevalecido como figura del espíritu nacional, sobre el de la Crónica rimada, contra quien luchó durante algunos siglos» (Agustín Durán, ed., Romancero general o colección de romances castellanos anteriores al siglo XVH, tomo II, en Biblioteca de Autores Españoles [tomo XVI], Madrid, Imprenta de los sucesores de Hernando, 1912 [primera edición 1851], págs. 849-850 [regularizo los acentos]).

${ }^{3}$ Conde de Puymaigre, Théodore J. Boudet, Les vieux auteurs castillans, volumen I, $2^{a}$ edjción, Paris, Nouvelle Librairie Parisienne, 1888 (primera edición 1861), pág. 185.

4 Ibidem, pág. 195.
}

RFE, LXXXIII, 2003, 3.०-4. ${ }^{\circ}$, págs. $261-279$ 
héroe de las Mocedades y el Cid mesurado del Poema, aduciendo que aunque en el joven Rodrigo resaltaba «cierta ferocidad ingénita» de la cual no quedaba vestigio alguno en el debelador de Valencia, existía en el fondo de ambos caracteres una «estrecha semejanza» que nos da a conocer la unidad interna de la tradición ${ }^{5}$. El estudioso español atribuía la «inmensa distancia» que separa al Rodrigo de las Mocedades del héroe maduro del Poema al abismo que generalmente existe entre la primera y la última edad del hombre. Sin embargo, encontraba en ambos «[i]gual grandeza de alma, igual lealtad e igual esplendidez y desprendimiento», reiterando que el joven que lava «con la sangre del poderoso conde de Gormaz la afrenta de su débil y anciano padre» es el mismo que en Santa Gadea se había atrevido a exigir al rey Alfonso el terrible juramento, sin temer «ni su poder ni su ira» ${ }^{6}$.

A fines del siglo XIX y principios del XX se siguio buscando una explicación (o una justificación) al carácter rebelde e impetuoso que presentaba Rodrigo en las Mocedades. Manuel Milá y Fontanals opinaba que «[l]os raptos violentos y que bien pueden llamarse extravagantes de independencia caballeresca en el joven Rodrigo [...] y la índole de algunos hechos como la deshonra de la doncella saboyana y el desacato al Papas debían atribuirse al espiritu de oposición a los relatos franceses que cantaban las conquistas de Carlomagno en España ${ }^{7}$. Indicaba, además, que en los tiempos de su decadencia la épica francesa daba frecuentes ejemplos de semejante proceder.

El juicio crítico más severo contra la figura del joven Rodrigo fue emitido por Ramón Menéndez Pidal, quien veía en las Mocedades los síntomas de un debilitamiento del género épico. El erudito español creía que el carácter «burdamente exagerado» del héroe de las Mocedades, que «no sabe hablar sino con desplantes de altivez, saña y fanfarronería, lo mismo contra su rey que contra el rey de Alemania, contra el papa y hasta contra doña Jimena», se debía al gusto decadente de esa época (fines del siglo XIV o principios del XV), cuando ya la tradición de las gestas se hallaba muy debilitada en España ${ }^{8}$.

\footnotetext{
5 José Amador de los Ríos, Historia critica de la literatura española, volumen III, Madrid, Imprenta de José Rodríguez, 1863, págs. 78-79 (regularizo los acentos).

6 En apoyo de su juicio, Amador de los Ríos cita el testimonio de Rodrigo Jiménez de Rada en De rebus Hispaniae, lib. VI, cap. XX: «Cum nemo vellet ab eo [Aldefonso] recipere iuramentum, ad recipiendum se obtulit Rodericus Didaci Campiator. Unde et postea licet strenuus, ron fuit in eius occulis gratiosus" (ibfdem, pág. 67, nota 1 ).

7 Manuel Milá y Fontanals, De la poesía heroico-popular castellana, Barcelona, Librería de Alvaro Verdaguer, 1896, pág. 255 (regularizo los acentos). Más adelante, Milá vuelve a explicar la conducta del joven Rodrigo como producto de las influencias anárquicas de la aristocracia y de los cantos franceses (ibldem, pág. 257).

${ }^{8}$ Ramón Menéndez Pidal, Poesía juglaresca y origenes de las literaturas románicas, 6" edición, Madrid, Instituto de Estudios Políticos, 1957 (primera edición: Poesía juglaresca y juglares, 1924), pág. 316.
} 
En la segunda mitad del siglo XX, cuando las Mocedades volvieron a estudiarse con más rigor, el problema de la caracterización del joven Rodrigo vino a ocupar de nuevo a los críticos. En efecto, en la mayoría de los estudios dedicados a la obra encontramos alguna indicación en este sentido: Samuel Armistead destaca «the hero's characteristic defiance of royal authority»'; Jole Scudieri Ruggieri señala que en las Mocedades el mayor héroe nacional de España aparece «trasformato in tutore dispotico di un inesperto adolescente [el rey]» ${ }^{10}$; Alan Deyermond, en su muy importante monografía, enumera los distintos episodios que muestran el deterioro de la personalidad del joven Rodrigo. Éste profiere insultos y amenazas, además de mostrarse prepotente y arrogante con el rey, con el papa y hasta con Jimena ${ }^{11}$. El mismo juicio expresan Louis Chalon, Thomas Montgomery y Matthew Bailey ${ }^{12}$.

A pesar de la coincidencia casi unánime de la crítica, en un estudio reciente Eukene Lacarra Lanz ha cuestionado esta visión tradicional del protagonista de las Mocedades al argüir, como Amador de los Ríos, que «the poet of M[ocedades deI R[odrigo] presented Rodrigo as a loyal vassal, and in that respect did not depart substantially from the political discourse of the earlier epic and historiographic traditions» ${ }^{13}$. Según Lacarra, las diferencias entre el joven Rodrigo y el Cid del Poema se deben a que en las Mocedades el joven caste-

9 Samuel G. Armistead, «The Structure of the Refundicion de las mocedades de Rodrigo», Romance Philology, XVII, 1963, pág. 340.

10 Jole Scudieri Ruggieri, "Qualche osservazione su Las mocedades de Rodrigo", Cultura Neolatina, XXIV, 1964, pág. 129.

"El estudioso británico indica que Rodrigo «insults his father in public, insults and threatens his king, treats his bride with extreme abruptness [...] Rodrigo seizes almost every opportunity of humiliating King Fernando and asserting his own superiority. He violates sanctuary in order to capture one of the Counts who has plotted against him. When he has defeated the Count of Savoy, he gets the Count's daughter into his power by promising that Fernando will marry her (she had been offered as a bride to Rodrigo himself), and then insists that Fernando should make her his mistress. Finally, he insults the Pope and violently opposes any suggestion of a truce» (Alan D. Deyermond, Epic Poetry and the Clergy: Studies on the «Mocedades de Rodrigow, Londres, Támesis, 1969, pág. 19).

12 Chalon describe al joven Rodrigo como «un personnage brutal et arrogant, insupportable par son insolence, rebelle à toute autorité, prompt à l'injure et à la provocation» ( $L$ 'histoire et l'épopée castillane du Moyen Age: le cycle du Cid; le cycle des comtes de Castille, Paris, Champion, 1976, pág. 386). Montgomery añade que el joven héroe es presentado como «the uncouth and invincible adolescent who is offensive to his father, his King, and his would be wife», aunque matiza este juicio al señalar que «at points he is transforned into a very charitable or a very clever champion» («Some Singular Passages in the Mocedades de Rodrigo», Joumal of Hispanic Philology, VII, 1983, pág. 122). Bailey, por su parte, subraya que lo que caracteriza a Rodrigo en las Mocedades es el desprecio al rey y la hostilidad hacia la nobleza, además de una actitud independiente que lo define en sus relaciones ( LLas asonancias inusitadas de las Mocedades de Rodrigon, Revista de Poética Medieval, III, 1999, pág. 30).

${ }_{13}$ Eukene Lacarra Lanz, «Political Discourse and the Construction and Representation of Gender in Mocedades de Rodrigon, Hispanic Review, LXVII, 1999, pág. 469. 
llano es presentado como un niño de doce años que debe aprender que la obediencia a la autoridad real es más importante que los intereses personales o familiares. El punto esencial para el poeta serfa demostrar que el bienestar del reino depende de una relación armónica entre el rey y sus vasallos ${ }^{14}$.

Teniendo en cuenta estas opiniones divergentes, la primera conclusión que podemos sacar es que el protagonista de las Mocedades es una figura problemática y compleja que merece que volvamos a ocuparnos de él.

Rodrigo se presenta en las Mocedades como miembro de un importante linaje castellano: es nieto de Laín Calvo, uno de los míticos jueces de Castilla. Diego Laínez, su padre, se ha casado con Teresa Núñez, hija del conde Ramón Álvarez de Amaya y nieta del rey de León (vv. 235-236). En las cortes de Zamora, el rey Fernando reconoce el poder y la influencia de los hijos de Laín Calvo y los invita a ayudarle a gobernar el reino:

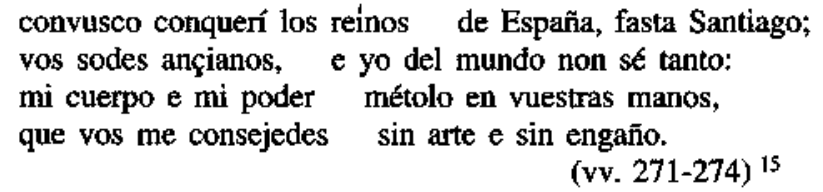

Aunque Fernando es un rey joven e inexperto ("yo del mundo non sé tanton), con la ayuda de los hijos de Laín Calvo ha conquistado los reinos de sus hermanos, León y Navarra. Además, se dice que «bien ordenó el rey su tierra» confirmando los fueros y privilegios otorgados por su padre y su abuelo (vv. 283-285). En esta sección del poema parece confirmarse la opinión de Lacarra. En efecto, aquí el poeta «represents the well-being of the kingdom as dependent on a close and loyal collaboration between the monarch and his vassals». Pero no hay que olvidar que en este caso es el rey el que reconoce (ha aprendido) que necesita y debe obedecer al poderoso clan castellano (v. 273, y otra vez en el v. 279).

Rodrigo, como el rey, también es muy joven -tiene apenas doce añospero muestra, sin embargo, arrojo y valor sin igual, además de una gran independencia y firmeza de carácter. A pesar de la oposición paterna (v. 322), de-

\footnotetext{
14 Lacarra sethala que «[t]he poet represents the well-being of the kingdom as dependent on a close and loyal collaboration between the monarch and his vassals, and proposes to demonstrate this through the relationship between King Fernando and Rodrigo. Introduced as two youths of similar age, they join efforts in fighting the Moors and Christians who threaten Castile [...] This cooperation makes final victory possible, and proves to be equally beneficia] for the king and his vassal. Fernando wins the title 'par de emperador' (v. 787) and Rodrigo is rewarded by the king with the office of 'alférez real,' the highest military honor» (ibidem, págs. 476-477).

15 Las citas han sido tomadas de la edición de Carlos y Manuel Alvar, Las mocedades de Rodrigo, en Épica medieval española, Madrid, Cátedra, 1991, págs. 99-162.
} 
cide combatir contra los enemigos de su familia y en su primer enfrentamiento armado mata al conde Gómez de Gormaz, que había ofendido a su padre, y apresa a sus dos hijos ${ }^{16}$. Por otra parte, Rodrigo es capaz de mostrar compasión por las hijas del conde que reclaman la libertad de sus hermanos. En efecto, el joven increpa a su padre por haber dado una respuesta evasiva a las muchachas:

Parat mientes al mundo, señor, por caridat:

non han culpa las fijas por lo que fizo el padre;

datles a sus hermanos, que muy menester los han;

contra estas dueñas, mesura devedes catar.

$$
\text { (vv. 350-353) }
$$

Según Georges Martin, en este episodio la personalidad de Rodrigo se afirma a expensas del padre ${ }^{17}$.

La misma firmeza e independencia va a mostrar Rodrigo frente al rey Fernando. Cuando Diego Laínez recibe el mensaje del rey convocándolo a la corte, siente gran inquietud y previene a su hijo:

témome de aquestas cartas, que andan con falsedat, et d'esto los reis muy malas costumbres han: al rey que vos servides, servillo muy sin arte, assí vos guardat dél commo de enemigo mortal; fijo, passat vos para Faro, do vuestro tío Ruy Laínez está. (vv. 395-399)

Pero aunque el padre trata de evitar que su hijo se presente con él ante el rey, Rodrigo insiste en acompañarlo con 300 caballeros armados. El joven no sólo está dispuesto a enfrentarse al rey, sino que analiza con sus hombres la posibilidad de matarlo si Fernando intenta aprehender a su padre (vv. 413-420) ${ }^{18}$.

${ }^{16}$ No me parece correcta la interpretación de John Gornall del v. 321 «nunca se viera en lit, ya quebrávale el corazón» ( TThe Cid's Youthful Deeds: Decadent Mocedades or Pristine Enfances?», Journal of Hispanic Research, III, 1994-1995, pág. 70). En mi opinión, al joven Rodrigo se le «quiebra el corazón» porque aún no ha participado en ningún conbate (cosa que desea), no porque sienta temor. Tampoco creo que en las Mocedades se presente a Rodrigo como pequeño de talla o dependiendo de su madre, como aduce Gomall (ibídem, págs. 71-72).

${ }^{17}$ Es evidente, en opinión de Martin, «que ce qui guide son comportement [de Rodrigo] est la haute idée qu'il se fait, ou veut donner, de celuj-ci. En vếrité, rivalités et altercations sont l'effet du double impératif à quoi les Enfances soumettent leur héros: donner la mesure de sa propre valeur et, dans le même temps, affirmer celle de ses ancêtres» (Les juges de Castille. Mentalités et discours historique dans l'Espagne médiévale, Paris, Séminaire d'études médiévales hispaniques de l'Université de Paris-XIII, 1992, pág. 512).

${ }^{18}$ La decisión es sin lugar a dudas muy grave y Rodrigo intenta justificarse alegando que ni él ni sus hombres son vasallos del rey, y añade que más traidor serfa Femando si matara a su padre. 
En la corte, la entrada de Rodrigo causa «grant pavor» (v. 424), y cuando después de una primera negativa el joven se inclina para besarle la mano al rey, también éste se siente «mal espantado» (v. 428). En ese momento se produce la famosa declaración de Rodrigo: «Querría más un clavo/ que vos seades mi señor nin yo vuestro vasallo:/ porque vos la bessó mi padre soy yo mal amanzellado" (vv. 430-432) ${ }^{19}$.

A pesar de su gravedad, este desacato no parece gratuito. El propio Diego Laínez ha prevenido a su hijo contra el rey, y Fernando ha dado numerosas muestras de debilidad e incompetencia: al asustarse ante la presencia del joven Rodrigo; al confesarle a Jimena que teme que los castellanos se alcen contra él si castiga al hijo de Diego Laínez por la muerte de su padre; al reconocer ante la corte «yo del mundo non sé tanto» (v. 272). Y aunque Rodrigo no le besa la mano, Fernando lleva adelante los esponsales del joven rebelde con Jimena. Una vez terminada la ceremonia, Rodrigo impone sus condiciones: no va a besarle la mano al rey ni a consumar el matrimonio con Jimena hasta lograr la victoria en cinco lides campales, es decir, hasta haber probado suficientemente sus cualidades guerreras en el campo de batalla.

Después que Rodrigo derrota a tres arrayaces moros en la primera de las cinco lides, se produce un nuevo enfrentamiento con el rey, quien le reclama el quinto del botín. Rodrigo se niega a entregárselo pues quiere repartirlo entre sus hombres «que assaz lo han lazrado» (v. 494), y se niega también a entregar al moro Burgos de Ayllón, aduciendo que «fidalgo a fidalgo, quandol' prende non deve dessonrrarlo» (v. 500). En este pasaje Rodrigo parece burlarse del rey, pues se muestra dispuesto a repartir diezmos y soldadas pero no a entregar el quinto que le reclama Fernando. La repetición de la frase «solamente non sea pensado" ante cada pedido del rey subraya la actitud desafiante de Rodrigo, a lo que debe sumarse la reacción que provocaría en un auditorio medieval la resignación de Fernando, puesto que el rey, incapaz de imponer su voluntad, acepta la decisión de Rodrigo. Éste se muestra, en cambio, generoso con el rey Burgos, al que libera y promete protección (vv. 509-510). Como respuesta a tal gesto, el rey moro se declara vasallo de Rodrigo (vv. 516-517). Las hazañas militares y la riqueza del joven héroe crecen, en tanto la figura del rey se debilita más y más. Pero, además, se pone en evidencia que Rodrigo se rige por un código caballeresco según el cual el rey no tiene el primer lugar en la sociedad si no es capaz de liderar en el combate; su sistema de valores tiene

19 Martin analiza el significado político de la negativa de Rodrigo a besarle la mano al rey, concluyendo que «le Poème [jas Mocedades] interrogue les fondements de l'autorité politique et voit le pouvoir du seigneur dépendre de l'adhésion du sujet. Cette disjonction fondatrice s'illustre traditionnellement dans le rejet de la seigneurie royale léonaise par le comte Ferrand Gonzalez» (op. cit., pág. 503). 
como parámetro principal la capacidad para realizar proezas en el campo de batalla.

Poco tiempo después Fernando sufre una nueva afrenta: el conde Martín González de Navarra lo desafía y ninguno de sus vasallos acepta lidiar por él. Cuando Rodrigo llega a la corte y ve al rey «muy triste», promete castigar a quien lo ha ofendido. Este breve episodio pone al descubierto la cobardía de la alta nobleza cortesana que se muestra incapaz de defender al rey. A la falta de valor de la alta nobleza se opone la valentía y el arrojo del joven héroe, miembro de la baja nobleza, quien acepta «de grado» el desafío. El rey Fernando, por su parte, se muestra temeroso y melancólico, e incapaz de controlar a sus vasallos. Son los aguerridos castellanos del linaje de Laín Calvo los que van a salvarlo una y otra vez.

En el combate contra los cinco reyes moros que han invadido el territorio cristiano se pone de manifiesto una vez más el contraste entre la conducta de la alta y la baja nobleza. En esta batalla mueren el padre y los tíos de Rodrigo. Pese al profundo dolor que le causan estas muertes, el joven héroe logra sobreponerse y vencer a los reyes moros (vv. 695-698). Los condes Garci Femández y Jimeno Sánchez, en cambio, se venden a los enemigos moros, y es Rodrigo quien «tan sañudo e tan irado» (v. 702) los persigue implacablemente. Para atrapar a uno de ellos «ovo de ronper la iglesia» (v. 712) donde el conde se había refugiado ${ }^{20}$. Sin embargo, Rodrigo no mata a los condes traidores, como cabría esperar, sino que los lleva a la corte para que sean juzgados.

También los hijos del conde Pedro de Campó se rebelan, aprovechando la ausencia de Rodrigo. Los hijos del conde invaden Palencia y echan al obispo. Cuando éste se dirige a la corte para presentar sus quejas al rey, Fernando una

\footnotetext{
${ }^{20}$ La violación de santuario era un pecado grave por el cual el propio rey Sancho, de acuerdo con la leyenda «oficial» acerca del descubrimiento de la tumba de San Antolín (diferente de la que se narra en las Mocedades), había sido castigado por Dios. Esta leyenda aparece por primera vez en el Toledano, quien cuenta que un día, mientras perseguía a un jabalí, el rey Sancho entró a una cripta donde había un altar en honor del Santo. Cuando el rey intentó matar al jabalí en el santuario, se le paralizó el brazo. Una aventura muy parecida se atribuye en el Poema de Fernán González al conde castellano. En esta versión se especifica que el jabalí «metio s' tras el atar» (c. 227d) (Poema de Femán González, Juan Victorio, ed., Madrid, Cátedra, 1990). El mismo detalle aparece en las Mocedades. En efecto, Rodrigo saca al conde traidor que se ha refugiado en la iglesia «de tras el altan, donde el muy cobarde se había escondido (v. 713). Es probable que el detalle provenga del Poema de Femán González, que el autor de las Mocedades conocía muy bien. Para un público familiarizado con la leyenda, el hecho de que el conde se comportara como el jabalí resultaría cómico, además de subrayar su cobardía. Precisamente por ser muy popular la leyenda «oficial» del descubrimiento de los restos de San Antolín (la del jabalî), nuestro poeta babría creado una nueva versión, más creíble, del descubrimiento de la tưmba (véase Deyermond, op. cit., págs. 83-92). Según la nueva versión, al hundirse la mula en la que cabalgaba el rey se habría descubierto una cueva con los restos del Santo. Otra razón que puede haber contribuido a que el autor de las Mocedades creara esta nueva versión de la leyenda es que Rodrigo iba más tarde a violar un lugar sagrado sin recibir por ello castigo alguno.
} 
vez más declara su impotencia: «Et dixo el rey: 'Muchas cossas que yo non puedo fazer ¡mal pecado!'» (v. 743). El único que podría resolver el conflicto es Rodrigo (v. 747).

Pero la amenaza mayor que va a tener que enfrentar Fernando no proviene de la alta nobleza ni de los moros, sino de la alianza del rey de Francia, el emperador alemán, el patriarca y el papa, quienes pretenden que los cinco reinos de España paguen un tributo anual. La reacción del rey Fernando es risible:

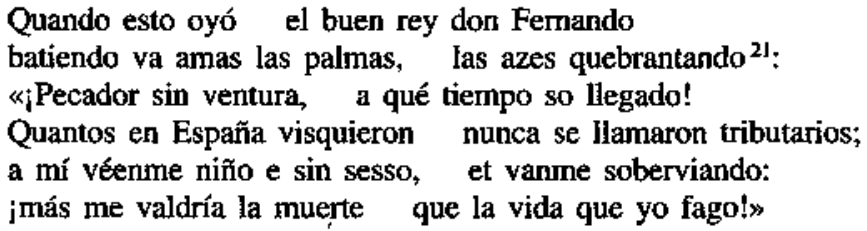

Rodrigo, en cambio, confiado en sus fuerzas, está dispuesto a enfrentarse al poderoso enemigo. $\mathrm{Y}$ aunque Femando se muestra animoso antes de la batalla con el conde de Saboya, ninguno de sus hombres parece querer seguirlo y el rey se hunde nuevamente en la melancolía (vv. 851-858). Fernando decide entonces nombrar alférez a Rodrigo, pero éste rechaza el honor (vv. 864-870) ${ }^{22}$, a pesar de lo cual es una vez más el joven castellano, que ni siquiera había sido armado caballero hasta ese momento, quien con una seña improvisada va a vencer al conde de Saboya. Creo que en estos incidentes se vuelve a poner de manifiesto la cobardía de «tanto omne rico e tanto conde et tanto poderoso fijodealgo», rasgo que contrasta con la valentía y el arrojo de Rodrigo, quien rechaza los honores pero no la lucha.

La aparición de Pero Mudo en este episodio reintroduce el tema del linaje aguerrido e independiente de Laín Calvo. Pero Mudo, después de protestar por el trato que ha recibido hasta ese momento, se muestra muy valiente. El joven es hijo ilegítimo de un hermano de Rodrigo y una labradora, lo que no le im-

\footnotetext{
21 Es difícil interpretar el significado del segundo hemistiquio de este verso, teniendo en cuenta que «az» es la 'tropa de caballeros tendidos en línea de batalla' (según Ramón Menéndez Pidal en el vocabulario de su edición del Cantar de mio Cid, volumen II, en Obras completas de R. Menéndez Pidal [volumen IV], $4^{2}$ edición, Madrid, Espasa-Calpe, 1969, pág. 492). Esta es la acepción que se halla en los glosarios de las ediciones de las Mocedades de Juan Victorio y Carlos y Manuel Alvar. Fórmulas similares se utilizaban para describir el desarmollo de los combates. Juan Victorio interpreta que el rey «[v]a dando palmadas por entre los asistentes» (Moce dades de Rodrigo, Madrid, Espasa-Calpe, 1982, pág. 65, nota 763). Es posible que haya un error en el manuscrito y que deba leerse «las [f]azes quebrantandon, es decir que el rey, como si fuera una mujer, se rasga las mejillas con desesperación.

22 Lacarra, en su estudio, no tiene en cuenta este detalle, como tampoco el desacuerdo final entre Fernando y Rodrigo acerca de las treguas, que analizo más adelante.
} 
pide llegar a ser porta-estandarte de su tío ${ }^{23}$. El tema vuelve a aparecer poco después, cuando Rodrigo responde al mensaje del conde de Saboya rebajando sus propios orígenes ${ }^{24}$. Las palabras de Rodrigo están cargadas de sarcasmo, pues el joven pretende humillar al conde al presentarse como «fijo de un mercadero, nieto de un çibdadano» (v. 919), es decir, como un contendiente indigno de luchar contra un miembro de la alta nobleza francesa. Sin embargo, estas palabras contienen su parte de verdad, pues Rodrigo no pertenece a la alta nobleza de título. Por otra parte, este episodio nos trae a la memoria el v. 308 , en el cual el conde de Gormaz llama despectivamente al padre de Rodrigo «fijo del alcalde çibdadanom. En las Mocedades, estos personajes de la baja nobleza que no pertenecen al círculo íntimo de la corte son los más valientes.

Rodrigo vuelve a humillar al conde de Saboya al rechazar a su hija y ofrecérsela, en cambio, al rey Fernando, quien también la rechaza aduciendo que «por conquerir reinos vine ać, ca non por, fijasdalgo» (v. 989). Creo que, dadas las circunstancias, la respuesta del rey podría interpretarse en la época como una falta de hombría, puesto que Femando no está rechazando una propuesta del conde de Saboya, el enemigo vencido que ofrece a su hija en matrimonio a cambio de su libertad, sino de Rodrigo, que entrega a la muchacha para que el rey se vengue en ella de las ofensas recibidas. Ante la insistencia del joven castellano, Femando decide deshonrar a la saboyana, acto que es interpretado como un justo castigo para los que pretendían que España les entregara, como parte de un tributo anual, quince doncellas vírgenes.

Entre tanto, Rodrigo marcha a París donde desafía a los doce pares, pero el rey de Francia le contesta que sólo el rey Fernando puede lidiar contra ellos. Esta respuesta, humillante para el joven héroe, parece implicar que sólo el rey de España es de alcurnia suficiente para enfrentarse de igual a igual con la alta nobleza francesa. El rey de Francia no reconoce las hazañas guerreras de Rodrigo como mérito que lo eleva a la altura de los linajudos pares franceses.

El papa también es presentado en este episodio de forma negativa: es el que concibe el plan de ofrecerle una tregua al rey Fernando, pero con la inten-

${ }^{23}$ Georges Martin, siguiendo a Armistead, cree que hay una repetición errónea en el manuscrito (vv. 886-887) y que en el texto original es el padre de Pero Mudo el que es presentado como hijo bastardo de Diego Lánez y una labradora (op. cit., pág. 537, nota 142). De esta forma se ajustaría lo que dice el poema a la Crónica de Castilla y la Crónica de 1344, donde se cuenta que, antes de casarse, Diego Laínez violó a una villana y tuvo un hijo con ella. Pero teniendo en cuenta que hay numerosas divergencias entre el poema y las crónicas, y también en las crónicas entre sí, su argumentación no me parece convincente. De todas formas, si el hijo ilegítimo fuera el padre de Pero Mudo y no éste, el cambio no afectaría mi interpretación.

24 Acerca de los personajes de origen ilegttimo o incierto, Deyermond señala que «[t]he hero of humble or mysterious origins is a stock folklore figure who appears frequently in medieval literature both in Spain and elsewhere: Fernán González, Mudarra, Bernardo del Carpio, Amadís, King Arthur, Charlemagne, Girart de Viane, and Roland in some works» (op. cit., pág. 182). 
ción de hacerle más tarde la guerra y apoderarse de su reino (vv. 1074-1081). Rodrigo aconseja a Fernando que se muestre «muy bravo» y pida batalla para el día siguiente, pues intuye que esos hombres «muy leídos» van a tratar de engañarlo (vv. 1089-1092).

Los ejércitos están a punto de enfrentarse por segunda vez cuando nace el niño que el rey ha concebido con la hija del conde de Saboya, y Femando decide otorgar las treguas que le reclaman sus enemigos pese a la oposición de Rodrigo. El texto se interrumpe aquí, pero creo que el pasaje final pone en evidencia una vez más la debilidad del rey Fenando, que cede a las demandas de sus enemigos y otorga treguas a todos los presentes ${ }^{25}$.

En mi opinión, todos estos episodios prueban suficientemente que en las Mocedades Rodrigo es presentado como un joven rebelde que desafía a la autoridad — su padre, el rey Fernando, el papa, el rey de Francia- pero que, sin embargo, nunca traiciona a su, rey. Por el contrario, Rodrigo es el único entre todos los vasallos del rey Fernando decidido a enfrentar a sus enemigos. Es el mejor de un linaje, los descendientes de Laín Calvo, que ha probado una y otra vez en el campo de batalla su valor excepcional. Aunque Rodrigo es muy joven, aparece siempre resuelto, seguro de sí mismo y es, claro está, invencible. El rey Fernando, joven también, hace un triste papel junto a Rodrigo, mostrándose con frecuencia irresoluto, melancólico y débil. Pese a que desciende del ilustre linaje que logró la independencia de Castilla, Fernando se muestra repetidamente incapaz de defender su reino. Cuando logra conquistar León y Navarra con la ayuda de los hijos de Laín Calvo, reconoce a León como «cabeza de todos los reinados» (v. 276), lo que probablemente deba interpretarse como una traición a los castellanos ${ }^{26}$. De ahí en más no vuelve a mostrar las características que esperaríamos en un rey medieval y, aunque busca permanentemente el consejo y la ayuda de Rodrigo, la relación entre ellos es inevitablemente conflictiva ${ }^{27}$.

\footnotetext{
${ }^{25}$ Nuevamente se utiliza la repetición («por amor de», vv. 1157, 1165, 1168, 1169; «quatro años», vv. 1163, 1166, 1168) para subrayar la debilidad del rey, asf como la enormidad de la concesión otorgada.

${ }^{26}$ Esto explicaría la desconfianza del padre de Rodrigo al recibir el mensaje del rey convocándolo a la corte. Ej conflicto entre León y Castilla ya había aparecido antes en el poema, cuando Sancho Abarca, rey de Castilla y León, desampara a los castellanos «porque era León cabeza de los reinados» (v. 207). Esto da lugar a que se rebelen los castellanos, liderados, precisamente, por los descendientes de Laín Calvo (vv. 208-210).

${ }^{27}$ Según Georges Martin, aunque en las Mocedades aparece esporádicamente la figura de Fernando I tal como la concibieron los compiladores alfonsíes - un rey fuerte y piadoso, valiente, ejemplar - en el poema se impone la imagen de un rey xjeune, faible et indécis, agressé de toutes parts, confronté à une noblesse qui le menace ou le désarme, toujours en quête de conseils et d'appuis, remettant finalement son pouvoir aux mains de l'homme fort qu'est Rodrigue» (op. cit., pág. 465). Martin relaciona esta visín de la monarquía con la crisis que se produjo durante la minoría de Fernando IV (1295-1301), época en la cual, según este crítico, se habría compues-
} 
Varios críticos - Jole Scudieri Ruggieri, Giorgio Perissinotto, Alan Deyermond, Juan Victorio, Georges Martin - han analizado el texto de las Mocedades asociándolo a un contexto histórico determinado. Estos estudiosos relacionaron los conflictos reflejados en el poema con diversas crisis socio-políticas de los siglos XIII y XIV: los primeros años del reinado de Femando III, la reconquista de Sevilla llevada a cabo por el rey Santo, las vicisitudes de la diócesis de Palencia, los conflictos de Pedro el Cruel con su medio-hermano Enrique de Trastámara y la minoría de Fernando IV. Por mi parte, quisiera analizar los modelos literarios en los que se inspiró el poeta para articular su visión de un monarca débil e irresoluto en conflicto con un poderoso vasallo.

Si dejamos de lado la introducción, en el relato de las mocedades propiamente dichas no se mencionan personajes históricos sino literarios: los de la tradición cidiana y los de cantares de gesta franceses (los doce pares, el palazín de Blaya, Almerique de Narbona) ${ }^{28}$. Varios eruditos han indicado, además, que es posible que exista una conexión entre Rodrigo y el rey Fernando y personajes de la épica francesa ${ }^{29}$. Ya a mediados del siglo XIX Agustín Durán señalaba: «[p]arécese mucho, contra toda verdad, este rey Fernando, al falso Carlo-Magno que fabricaron los poetas afectos al feudalismo que humilló a los sucesores de este gran emperadors ${ }^{30}$. Poco después, el conde de Puymaigre añadía: «nous voyons le Cid, dans la Crónica rimada, cesser d'être un fidèle vassal et devenir un turbulent feudataire comme les quatre fils Aymon» ${ }^{31}$. Por otra parte, este crítico fue el primero en notar en el texto el uso de la palabra provenzal «jenzon» (v. 795), la mención de los doce pares y otras analogías, menos significativas, con los cantares de gesta franceses. Milá y Fontanals, como ya hemos indicado, explicaba el carácter violento del joven Rodrigo como producto de la influencia de la épica francesa ${ }^{32}$. Deyermond, a su vez,

to el poema. Scudieri Ruggieri, en cambio, cree que el texto refleja los conflictos que atravesó la monarquía durante la adolescencia de Fernando III (op. cit., pág. 133), tesis también sustentada por Giorgio Perissinotto, quien encuentra en los vv. 798-799 (según la edición de Carlos y Manuel Alvar) un indicio de que el poeta relataba sucesos protagonizados por Fernando I dejándose influenciar por la historia reciente del reinado de Fernando III («A propósito de los versos 793 y 794 de las Mocedades de Rodrigo», Cultura Neolatina, XXXIX, 1979, pág. 163). Sin embargo, me parece difícil que Fernando III el Santo, al que, según el mismo Perissinotto, la historia consagró como «el conquistador por excelencia» y cuyas hazañas estarían aún frescas en la memoria de la gente cuando se compuso nuestro poema, haya influido en la representación del rey «niño e sin sesson de las Mocedades.

${ }^{28}$ Algunos personajes de primera magnitud no tienen nombre, son simplemente «el papa», «el rey de Francia», «el emperador alemanom, etc.

${ }^{29}$ De la popularidad de los héroes de las chansons de gesse en la Península Ibérica da testimonio el propio Rodrigo en las Mocedades: «siempre ó dezir que Doze Pares avía en Françia» (v. 1048).

${ }^{30}$ Durán, op. cit., pág. 664, nota 57.

${ }^{31}$ Puymaigre, op. cis., pág. 3.

${ }^{32}$ Millá y Fontanals, op. cit., págs. 255, 257. 
analizó las referencias a personajes de las chansons de geste en las Mocedades, concluyendo que el poema «reflects, with varying degrees of accuracy and intensity, several French epic traditions, but it is fair to say that it shows rather less knowledge than might be expected in fourteenth-century Spain» ${ }^{33}$. Pero el único estudio, hasta el momento, dedicado a esclarecer la relación existente entre las Mocedades y las chansons de geste es el de John Gomall, quien encontró analogías entre la figura del joven Rodrigo y varios personajes de la épica francesa, en su mayoría pertenecientes al ciclo de Guillaume d'Orange. Quizá el aporte más significativo del trabajo de Gomall sea que por primera vez intenta explicar el texto de las Mocedades no como el producto tardío de un género en decadencia, sino dentro del marco específico de las enfances:

M[ocedades de] R[odrigo], as an epic poem, is not just a response to natural curiosity about the Cid's early life: it is an example of a sub-genre. Far from being an unfortunate lapse, it stands firmly within an heroic tradition of Youthful Deeds that goes back to the twelfth century ${ }^{34}$.

En mi opinión, tenemos que examinar más ampliamente la épica francesa, sin limitarnos a las enfances, si queremos encontrar las fuentes en las que se inspiró el autor de las Mocedades. Hay un buen número de chansons de geste que tienen como protagonistas a grandes barones feudales que se rebelaron contra la autoridad real.

La actitud de los poetas que componían extensas chansons en las que el rey era combatido y humillado, en tanto que los vasallos rebeldes eran elevados al rango de héroes, se ha explicado como producto del debilitamiento de la monarquía francesa durante los siglos XI y XII ${ }^{35}$. Pero Rodrigo, como hemos visto, no llega al extremo de combatir a su rey y, por el contrario, lo defiende de las agresiones de los condes rebeldes, de los ataques de los moros y de las ambiciones de otros potentados cristianos. Los paralelos más significativos con personajes de la épica francesa se encuentran si comparamos las Mocedades con los poemas protagonizados por Guillaume d'Orange, el hijo de Aymeri de Narbonne (el Almerique de Narbona de las Mocedades) ${ }^{36}$. Todo el ciclo de

\footnotetext{
${ }^{33}$ Deyermond, op. cit., pág. 185.

${ }^{34}$ Gomall, op. cit., pág. 77. Lacarra también rechaza el rótulo de «épica decadente» aplicado a las Mocedades, pero desde otro punto de vista. En su opinión, la evaluación negativa del poema por parte de la crítica se debe a motivos ideológicos y, en definitiva, a una interpretación equivocada del texto (op. cit., pág. 467).

35: Véase Martín de Riquer, Les chansons de geste françaises, $2^{*}$ edición, traducción de Irénée Cluzel, Paris, Nizet, 1968, pág. 227.

36 A propósito de este personaje. Scudieri Ruggieri sugirió que en las Mocedades se aludiría a una figura histórica específica: Amalric, vizconde de Narbona desde 1239 hasta 1270 y aliado de Alfonso X el Sabio. EI sobrenombre que se le atribuye en el poema, don Quirón, referiffa al famoso centauro a quien fue confiada la educación de Aquiles y pertenecería a un ámbito de alta
} 
Guillaume, compuesto de más de veinte chansons, celebra a una heroica familia, «le fier lignage», que encabeza la lucha contra los sarracenos de España y lleva a cabo la reconquista de grandes territorios que debieran haber sido liberados por Carlomagno o su hijo Luis, el desafortunado y timorato rey Luis que si puede de alguna manera llamarse rey es gracias, precisamente, a Guillaume. En estos poemas los barones luchan contra los sarracenos sin el apoyo del rey, pero no en franca oposición al monarca. Como puede observarse, hay muchas analogías con la actuación del joven Rodrigo en las Mocedades, que analizaremos más detenidamente a continuación.

En Les enfances Guillaume el protagonista es presentado como «uns des fiz Ainmeri le chasteinne,/ Qui tant jors tint Nerbonne an son demoinne,/ Qui tant ocist de la gent mecreande» (vv. 6-8) ${ }^{37}$. Es decir, importa en primer lugar establecer la ascendencia heroica del joven, tal como ocurre con Rodrigo en las Mocedades.

Cuando un mensajero llega a Narbona anunciando que Carlomagno quiere armar caballeros a los cuatro hijos mayores de Aymeri después de un período de servicio en la corte, todos se alegran excepto Guillaume, que en lugar de perder varios años en la corte del rey quiere probarse en el campo de batalla:

Fiz a putains, mavais garsons frarins,

La vostre anfance durait ele toz dis?

Or deüsiés chivelir devenir

Et garoieir paieins et Sarasins.

(vv. 77-80)

Esta es la primera impresión que recibimos de Guillaume: la de un joven violento e insolente que, como Rodrigo, rechaza la molicie de la vida cortesana

cultura (op. cit., págs. 135-136). Sin embargo, hay que tener en cuenta que el nombre Aimeric aparece con frecuencia entre los vizcondes de Narbona: Aimeric I, muerto en 1105; Aimeric II, muerto en 1134; Aimeric de Lara, hijo de Manrique de Lara, fue nombrado heredero de Narbona por su tía materna, la vizcondesa Ermengarde, en 1168. Después la dinastía de Narbona alternó los nombres Aimeric y Amalric (véase Riquer, op. cit., pág. 164). Me parece más probable que el poeta de las Mocedades aluda al famoso personaje de la épica francesa, que aparece además en dos romances castellanos con el nombre de Benalmenique o Almenique. Recientemente Madeleine Tyssens publić́ dos fragmentos de la Geste de Guillaume conservados en un manuscrito de la Biblioteca Nacional de Lisboa que pueden considerarse como un testimonio más de la difusión de las chansons del ciclo de Guillaume en la Edad Media, aunque por el momento no se ha podido fjjar la fecha exacta del manuscrito ( llaume [BNL, MSS. 258.42]», Cultura Neolatina, LXI, 2001, págs. 25-53). Agradezco a Anna Ferrari la noticia acerca de esta publicación.

37 Las citas han sido tomadas de la edición de Patrice Henry, Les enfances Guillatume, Paris, Société des Anciens Textes Français, 1935. Henry fecha la composición del texto que ha llegado a nosotros en la primera mitad del siglo XIII (ibidem, págs. XXX-XXXI). El autor, según el propio texto, fue «un moines de Saint Denise an France» (v. 3). 
pues tiene planes muy diferentes para su futuro. En efecto, Guillaume anuncia su resolución de emprender inmediatamente la conquista de Orange: «Juc' ai Orange ne panrai onkes fin, $/ \mathrm{Ne}$ revanrai si avrai tant conkis/ Qui bien porai trois mile honmes tenirs (vv. 91-93). No obstante, su padre logra convencerlo de que antes de llevar a cabo estas hazañas debería ser armado caballero por el emperador. Camino a la corte, Aymeri y sus hijos combaten contra 7.000 sarracenos y los vencen. Guillaume se entera por uno de ellos de la existencia de Orable «la belle» y le envía un mensaje anunciándole que va a matar a Thiébaut, su pretendiente, y la va a hacer su mujer (vv. 558-571). Aunque Orable se desmaya tres veces cuando oye el mensaje, poco después decide advertir a Guillaume que corre peligro, pues 15.000 sarracenos se dirigen a atacar su campamento (vv. 766-778). Este motivo -el de la joven que se enamora de su enemigo, en el cual reconoce al futuro héroe que llevará a cabo grandes hazañas, y traiciona a su familia por él- aparece también en las Mocedades. Es el «extraño caso» de Jimena, quien le pide al rey que la case con el hombre que ha matado a su padre. Aunque hay muchas diferencias entre la sarracena Orable y Jimena, ambos personajes comparten características importantes. Pero, además, hacia el final de Les enfances aparece otro personaje femenino que presenta analogías con la Jimena de las Mocedades: es Elisant, la hija de Yon de Gascogne, quien ha perdido a sus padres hace muy poco tiempo y le reclama al rey un marido (vv. 3380-3388). Carlomagno la casa inmediatamente con Buevon, hermano de Guillaume.

Cuando después de diversos incidentes Guillaume llega a la corte, se presenta ante Carlomagno mostrando gran rudeza y arrogancia: insiste en ser él quien entregue la espada al emperador en la ceremonia que se está llevando a cabo y, como no se le otorga lo que pide, recurre a la fuerza (vv. 2284-2298). Carlomagno declara que este «diable» debiera ser quemado (como el rey Fernando, quien llama a Rodrigo «pecado» cuando éste, después de haberse negado la primera vez a besarle la mano, se arrodilla por fin ante él). Pero en ese momento Ilega Aymeri y con su intervención la situación se resuelve pacíficamente (de forma similar se resuelve el caso de Rodrigo). Poco después llega a la corte de Carlomagno un campeón bretón que viene a desafiar a los franceses (vv. 2411-2412), pero nadie se atreve a enfrentarlo («Françoiz l'oïrent, mout en sont effraé» vv. 2418,2479 ) excepto Guillaume, que lucha contra él y lo mata. Los paralelos con el episodio del desafío de Martín González de Navarra en la corte del rey Fernando son numerosos ${ }^{38}$. Carlomagno quiere recompensar a Guillaume armándolo caballero, pero éste rechaza las armas que le ofrece el emperador: «Trop sont ligieres, ne m'aroient mestier;/ Bernart mon freire en

${ }^{38}$ En Le couronnement de Louis hay un desafío similar que analizaremos más adelante. 
faites chevalien (vv. 2545-2546). De la misma manera, Rodrigo rechaza el puesto de alférez que le ofrece el rey Fernando.

El que mejor parece haber comprendido a Guillaume en la corte del emperador es el abad de Saint-Denis, quien entrega las armas maravillosas del rey Alejandro al fiero joven:

Cist anfes est fel et desmesurables,

Maltalantis et fornant airrables;

Soz ciel n'ait home cui il portaist menaide.

Mais chargiez li vint mil homes as anme

Si l'anvoiez an Puelle ou an Calabre ${ }^{39}$ :

Illuec conquiere les chastelz et les marche

Et soit tot sien kanke il porait faire.

(vv. 2637-2643)

Finalmente, también Carlomagno reconoce la calidad extraordinaria de Guillaume y éste acepta las armas. Rodrigo, en cambio, no ha sido tan afortunado en la corte del adolescente rey Fernando.

El tema de la debilidad del monarca, que no aparece en Les enfances, se desarrolla en el ciclo de Guillaume a partir de Le couronnement de Louis, poema en el cual se ponen de manifiesto las diferencias entre la personalidad de Carlomagno, digno y consciente de los deberes de un rey ${ }^{40}$, y de su hijo Luis, todavía joven, a quien las responsabilidades del poder le causan temor. Según Dominique Boutet, esta imagen del rex puer, heredada de la retórica de los historiadores de la antigüedad más que de la realidad histórica del reinado de Luis el Piadoso, es tratada en estas chansons a la manera de un topos que se repite una $y$ otra vez ${ }^{41}$.

\footnotetext{
39 «Pulla e Calabra» se mencionan en las Mocedades entre los reinos que se han aliado contra los españoles (v. 830).

${ }^{40}$ En la ceremonia de coronación, Carlomagno le dice a su hijo: «Tort ne luxure ne pechié ne mener,/ $\mathrm{Ne}$ trä̈son vers nului ne ferez/ $\mathrm{Ne}$ orfelin son fié ne li toldrez» (vv, 65-67). Antes, el poeta había definido las cualidades del monarca ideal, subrayando que éste debía destacarse ante todo como un líder capaz de imponer su voluntad: «Reis qui de France porte corone d'or/ Prodom deit estre et vaillanz de son cors; / Et s'il est om qui li face nul tort// Ne deit guarir ne a plain ne a bos/ De ci qu'il l'ait o recreant o mort:/ S'ensi nel fait, done pert France son los;/ Ce dit l'estoire coronez est a torty (vv. 20-26). (Las citas han sido tomadas de la edición de Emest Langlois, Le couronnement de Louis, $2^{a}$ edición, Paris, Champion, 1984).

${ }^{41}$ Dominique Boutet, ed., Le cycle de Guillaume d'Orange, Paris, Lettres gothiques, 1996, págs. 6-8. Langlois también indica que la investigación de fuentes históricas de Le couronnement resultó negativa. En efecto, la coronación solemne de Luis tuvo lugar en el año 813 y los cronistas aseguran que la ceremonia no encontró oposición alguna. Por tanto, la traición del conde Arnéis debe ser una ficción de la leyenda o del poeta (Langlois, op. cit., pág. V). En la Peninsula Ibérica, el tema del «rey niño» aparece en la Estoria de España a propósito de la minoridad de Alfonso VIII, durante la cual dos poderosas familias castellanas, los Lara y los Castro, se dispu-
} 
Le couronnement de Louis es una de las chansons más antiguas del ciclo de Guillaume $^{42}$. El tema del poema es la defensa de Luis, todavía adolescente, contra sus enemigos internos (los vasallos rebeldes) y externos, al mismo tiempo que se consolida la solidaridad entre el emperador y el papa. Boutet encuentra en la obra una fuerte unidad ideológica: Guillaume aparece como el protector de la monarquía hereditaria a pesar de los errores y las debilidades de ésta ${ }^{43}$. En efecto, el poema comienza con la defensa del linaje real por parte de Guillaume cuando éste mata al conde Arméis, que pretendía ser coronado en lugar del hesitante Luis ${ }^{44}$. El joven rey, como Fernando en las Mocedades, decide ponerse bajo la protección del noble guerrero:

-En nom Deu, sire, et manaide et pitié.
Mes pere dit qu'estes bons chevaliers,
N'a tel baron soz la chape del ciel;
En vos vueil metre mes terres et mes fiez,
Ques me guardez, nobiles chevaliers,
Tant que je puisse mes guamemenz baillier. (vv. 218-223)

Guillaume acepta, pero antes de emprender nuevas empresas bélicas quiere cumplir con su promesa de ir en peregrinación a Roma (también Rodrigo debe aplazar su combate con el conde de Navarra para ir en romería a Santiago).

En uno de los episodios finales de Le couronnement, el rey Luis es desafiado por Gui d'Allemagne; el vencedor «aveas Rome quite et tot l'eritage» (v. 2397). Luis responde que no puede pelear contra Gui por ser muy joven, y pide a sus hombres que acepten el desafío en su lugar. Al ver que nadie se

taron la tutoría y la regencia del reino. Dice el cronista: «los comienços de los reyes et de su regnar nuncua o muy pocas vezes pueden seer sin discordia et sin contienda, et mayormientre en los reyes que niños comiençan a regnar, como en este rey don Alfonsso que non fincara de su padre mayor de cuatro años». La reflexión procede de don Rodrigo Jiménez de Rada (De rebus Hispaniae, lib. VII, cap. XV). (Citado por Fernando Gómez Redondo en Historia de la prosa medieval castellana, volumen I, Madrid, Cátedra, 1998, pág. 65).

42 Langlois la fecha hacia 1130 (op. cit., pág. VII), datación generalmente aceptada por la crítica (vếase Boutet, op. cit., pág. 73). Joseph Bédier, en cambio, opinaba que había sido compuesta hacia 1160.

${ }^{43}$ Op. cit. págs. 73-74.

4 Guillaume mata al conde en la iglesia donde tiene lugar la coronación, violando, como Rodrigo, un lugar sagrado; más tarde mata al traidor Richart junto a un altar (vv. 1957-1964). Este pecado es cometido frecuentemente por los vasallos rebeldes de la Épica francesa: Isembart incendia la abadía de Saint-Riquier; Raoul de Cambrai incendia la abadfa d'Origni, donde mueren cien monjas; Girart de Roussillon masacra a cien enemigos que se han refugiado bajo una cruz e incendia un monasterio con el abad y sus monjes. Creo que debemos interpretar estos episodios como el producto trágico de una monarquía débil o injusta que no logra imponer la ley, lo que lleva a los barones más valientes y osados a rebelarse y cometer actos desmesurados. 
ofrece, Luis llora desconsoladamente (vv. 2405-2413). En ese momento llega Guillaume, que se conmueve al encontrar al rey suspirando entre lágrimas y decide pelear por él. Este pasaje, como el de Les enfances que ya mencionamos, presenta numerosas analogías con el desafío del conde Martín González de Navarra en las Mocedades. En efecto, cuando el rey Fernando es desafiado por el conde ninguno de sus vasallos acepta pelear por él. El rey se muestra temeroso e incapaz de hacerse obedecer por sus vasallos. Rodrigo llega a la corte y encuentra a Fernando muy triste; sólo Rodrigo parece dispuesto a arriesgar su vida por él.

Además hay otros paralelos entre estos personajes: Guillaume, como Rodrigo, tiene un sobrino valiente e impetuoso, «li palazins Bertrans» (v. 2442) ${ }^{45}$; el rey Gaifier, al igual que el conde de Saboya en las Mocedades, le ofrece a Guillaume su única hija, que será la heredera de todos sus bienes. Guillaume, a diferencia de Rodrigo, acepta la proposición, pues como le advierte el papa «Bachelers estes, de terre avez mestien» (v. 1369). Sin embargo, la boda no se lleva a cabo puesto que Guillaume debe partir inmediatamente para socorrer al rey Luis.

En Le couronnement, Guillaume es el héroe joven e invencible que lucha infatigablemente contra musulmanes y cristianos para mantener en el trono a un rey «enfes» acosado por traidores que quieren aprovecharse de su debilidad. Rodrigo, en cambio, parece defender ante todo a su linaje y a Castilla, tanto del débil rey-niño como de nobles traidores y potencias extranjeras. Ocasionalmente se alía con alguno de éstos para lograr sus objetivos, pero lo que lo distingue a lo largo del poema es su fiera independencia y un código caballeresco que se rige exclusivamente por valores guerreros ${ }^{46}$.

En Le charroi de Nimes, otra chanson del ciclo de Guillaume, el rey Luis olvida a su fiel defensor en el momento de distribuir feudos entre sus vasallos. El altercado que se produce entre ellos a causa de esto no tiene igual en todo el género épico. Al entrar a la corte, Guillaume se niega a sentarse, rechazando la invitación del rey (v. 60) ${ }^{47}$. Con su negativa Guillaume muestra, como Rodrigo, su espíritu independiente y desafiante. En esta escena hay, además, una

\footnotetext{
${ }^{45}$ En las Mocedades se menciona a un misterioso «palazín de Blaya» (v. 834). Por ser Blaya la ciudad donde estaba enterrado Roland, se ha supuesto que el epíteto podría aludir a él (véase Deyermond, op. cit., págs. 183-184). Sin embargo, hay que tener en cuenta que la ciudad tiene un papel importante en otros poemas: Amis (en Amis et Amile) llega a ser conde de Blaya, así como Jourdain de Blaye, héroe del cantar homónimo (véase Scudieri Ruggieri, op. cit.. pág. 138).

${ }^{46}$ En numerosos textos medievales se atribuyeron estas características a los orgullosos castellanos que habían logrado primero independizarse del reino de León y tuego establecer su predominio sobre los otros reinos peninsulares.

${ }^{47}$ La citas han sido tomadas de la edición de Claude Lachet, Le charroi de Nimes, Paris, Gallimard, 1999. Lachet fecha la composición de la obra a mediados del siglo XII.
} 
inversión de roles, pues el rey se somete a la voluntad de su vasallo («Dist Looys: 'Si com vos commandez'», v. 62). A continuación Guillaume rechaza cada uno de los feudos que le ofrece el rey, pues no quiere «De veves fames, d'enfanz desheriten (v. 66) ${ }^{48}$, y enfurecido reprocha al rey Luis su poco valor:

\begin{abstract}
François le virent que ne valoies gaire:
Fere en voloient clerc ou abé ou prestre,

$\mathrm{Ou}$ te feïssent en aucun leu chanoine.
\end{abstract}

(vv. 166-168) ${ }^{49}$

Más tarde, Guillaume vuelve a aludir a la cobardía de Luis al recordar que en el enfrentamiento contra Gui d'Allemagne el rey huyó a pie (vv. 235-236), y que en la guerra contra «les Sarrasins, les Turcs et les Slaves» salió corriendo «comme coart levrien» ( $v$, , 361). A causa de su debilidad y poco valor el monarca no cumple con la obligación de proteger a sus vasallos.

Ante los reproches de Guillaume, el rey reacciona ofreciéndole un cuarto de su reino (v. 384). La enumeración incoherente de riquezas concedidas -abadías, mercados, clérigos, hombres de armas, damas, doncellas, caballos- y la repetición de la palabra «quart» sugieren la desmesura y el extravío del gesto del soberano. El episodio nos recuerda el pasaje final de las Mocedades, en el cual el rey Fernando otorga treguas a todos los presentes, tanto si se las han pedido como si no. En esos versos finales se repiten una y otra vez las frases «quatro años» (la duración de las treguas otorgadas) y «por amor de», poniendo de manifiesto, en mi opinión, la desmesura de tan extraordinaria concesión.

Después de salir del palacio, Guillaume, exasperado, amenaza con quitarle la corona a Luis (vv. 435-436), pero cambia rápidamente de parecer cuando su sobrino le recuerda que su deber es socorrer y ayudar al rey contra todos sus enemigos (v. 440).

Otro episodio de Le charroi que tiene un paralelo en las Mocedades es el pasaje en que Guillaume, para poder entrar a la ciudad sarracena de Nîmes, se hace pasar por un mercader. Esta presentación del héroe tiene un efecto cómi-

\footnotetext{
${ }^{48}$ La protección de los débiles y de los oprimidos, especialmente de los buérfanos y de las viudas, tiene su origen en el Antiguo Testamento. Esta obligación formaba parte de la misión real, como le indica Carlomagno a su hijo Luis en Le couronnement (vv. 153-154, 178-179), y también era un deber de los caballeros. En las Mocedades, Rodrigo cumple con esta obligación caballeresca al mostrarse piadoso con Jimena, cuando ella, después de la muerte de su padre, reclama la libertad de sus hermanos.

${ }^{49}$ En Le couronnement Carlomagno, furioso ante la cobardía de Luis, amenaza con hacerio campanero de una iglesia (vv. 95-98). Esta representación negativa de los clérigos, como personajes poco valientes y traicioneros, se encuentra a su vez en la épica castellana: es el caso del arcipreste lujurioso que quiere aprovecharse de la futura esposa de Fernán González, como así también del papa de las Mocedades.
} 
co, como cuando Rodrigo se presenta ante el conde Saboya haciéndose pasar por «fijo de un mercadero».

El topos de la debilidad y la ingratitud de Luis quedaba fijado en estos poemas e iba a ser una característica del rey en todo el ciclo de Guillaume. Las chansons del ciclo tienen, no obstante, la función de entretener y divertir más que la de profundizar en el tema del poder desde una perspectiva sociopolítica. En éstas se multiplican los episodios cómicos y maravillosos, signos visibles de una transformación estética del género épico. Lo mismo ocurre en las Mocedades, poema en el que abunda la ironía y donde el extenso episodio de la aparición de San Lázaro contrasta con la etérea visión del ángel Gabriel en el Poema de mio Cid, única irrupción de lo maravilloso en este texto.

En las Mocedades la ironía se usa para hostigar a la alta nobleza, que se muestra incapaz de renovar sus blasones por medio de nuevas hazañas guerreras, y para señalar las debilidades de un monarca melancólico y temeroso que no puede sostenerse en el trono sin la ayuda del joven castellano. Tanto el rey como la alta nobleza aparecen asociados con una política pro-leonesa y pactista (cuando no decididamente traidora), en tanto Rodrigo y su linaje representan la intransigencia de los aguerridos castellanos que llevaron adelante la Reconquista y el engrandecimiento de Castilla, en la tradición de las hazañas de Fernán González.

La falta del final del texto no nos permite saber cómo acababa el poema, pero me parece evidente que, como en muchas chansons francesas, la figura del rey y la alta nobleza quedaban irreparablemente rebajadas en su dignidad. Rodrigo, sin embargo, nunca traiciona a su rey, y con su insolencia y osadía obliga a Fernando a asumir la defensa de una España atacada por enemigos internos y externos. Rodrigo se constituye en héroe y emblema de una Castilla joven que con su invencible espíritu guerrero logró imponerse a moros y cristianos. 